\title{
The Regulation of All Pay Auctions: Is There Need for Greater Regulation of Online Auctioneers?
}

\author{
Michael D'Rosario \\ Department of Finance, Deakin Business School, Deakin University, Victoria, Australia \\ Email: michaeld@deakin.edu.au
}

How to cite this paper: D'Rosario, M. (2017) The Regulation of All Pay Auctions: Is There Need for Greater Regulation of Online Auctioneers? Theoretical Economics Letters, 7, 1201-1222.

https://doi.org/10.4236/tel.2017.75081

Received: January 28, 2017

Accepted: July 18, 2017

Published: July 21, 2017

Copyright $\odot 2017$ by author and Scientific Research Publishing Inc. This work is licensed under the Creative Commons Attribution International License (CC BY 4.0).

http://creativecommons.org/licenses/by/4.0/ (c) (i) Open Access

\begin{abstract}
Auctions are a ubiquitous process, with auctioneers playing a critical role in serving as a bridge between buyers and sellers, and as such assisting in the process of price discovery. Given this critical role, the regulation of auctions and auctioneers is of particular concern. The emergence of online selling has raised a number of pertinent questions about how the industry should be regulated. In particular so-called penny auctions (in economic parlance "unit bid auction") have raised a number of pertinent questions about consumer protections. Whether these online selling models constitute auctions, and whether they mirror "bricks and mortar" rivals remain pertinent questions. Moreover, the adequacy of the regulatory apparatus that moderates the activities of auctioneers operating within conventional "analogue markets" is uncertain when such apparatus is applied to "digital markets" involving online selling through auction like processes. The current study considers need for regulation of unit bit auction in light of the underlying economics of such auction models. The model suggests that enhanced disclosure and greater regulation may ultimately be necessary.
\end{abstract}

\section{Keywords}

Penny Auction, Game theory, Regulation

\section{Introduction}

We are observing a revolution of sorts, with many computer mediated technologies changing the way we do business. These disruptive technologies are forcing organizations to rethink the way that they engage and connect with other organizations and individuals, and pertinently changed the shape of business and commerce. This is particularly true in relation of the purchase of goods and 
services online. A number of disruptive business models have emerged, such as coupon based product and service acquisition, online (English and Dutch model) auction based selling, and in recent times variants on conventional auction models such as the penny auction model. Many of these models bear obvious and logical similarity with their "physical world" equivalents, but some are markedly different from their bricks and mortar equivalents.

Coupon based business websites benefit from being able to secure preferential pricing and discounts for their network of subscribers by virtue of their ability to generate promotional opportunities for their vendor partners. As such, coupon based business websites benefit from network effects associated with large networks, in this case a network of buyers looking for discounted goods and services. Such business models also evidence economies of scale, given that there is little by way of marginal cost associated with generating coupons, adding vendors and servicing the network of subscribers. As such the transition from a "bricks and mortar" business to "cyberspace business" is a relatively straightforward one. Online auction models have also burgeoned, disrupting a number of conventional auction houses and models for selling, like the popular paper based “Trading Post" model. Online auction models fall into two categories, the conventional English auction model typified by the popular online seller site eBay, and the all-pay auction model employed by auctioneers such as "Bidking.com.au".

The former model has become hugely popular online, with websites like eBay ranking amongst the most visited websites in the world. Given the obvious similarities between the online model and its bricks and mortar equivalent, it was perhaps anticipated that the transition would be somewhat straightforward. Yet, there remain some questions about the manner in which such models are regulated, particularly those beyond the well established players such as eBay. However, in the view of the author it is the emergence of the all-pay auction online (the most popular variant being the so called "penny auction") that is the greatest cause for concern for regulators.

Both the similarities and differences between conventional online auctions and penny auctions have been a cause of consternation for regulators. It is likely that most internet users would have a reasonable understanding of online auction models given the ubiquity of websites such as eBay, where items are placed for sale over a defined period and the party offering the highest bid during the bidding period has their bid consummated. This model as noted is strongly aligned to the English or traditional auction model that most consumers would have a strong familiarity with; where an auctioneer offers a good or service for sale on behalf of a vendor, and rivals offer bids on the item until a single buyer is left with the highest bid value. But consumers are less likely to be familiar with all-pay auction models where bidders acquire bid units that are expended as they bid for a particular good or service. A particularly popular variant of the all-pay auction is the online "penny auction". A penny auction is a stylised Tullock auction akin to a "war of attrition" game, where bidders acquire 
bid units, usually for a dollar, and expend each unit as they bid on a good or service, or even bids and monetary sums. Each successive bid also extends the time assigned to the auction process, and the auction ends when all parties to the bidding process expend their bid units or where, the bidders to the process lose their desire to maintain participation in the bid process.

Such models are growing in popularity given the seemingly low prices associated with goods and services advertised on promoter websites and the ease with which an auction model can be conceived, crafted, and administered online. The auction websites frequently assert that their prices are substantially lower than rival auction models, such as traditional (English) auction models (such as eBay); and in comparison to bricks and mortar sellers (such as Kmart or Target) and online sellers (such as Amazon). Penny auction websites unlike other traditional auction models benefit from the "sunk cost fallacy". However there appears to be a dearth of evidence noting any disclosure of the total spent on each item inclusive of the total bid tally, on online penny auction sites.

The model has met the ire of consumers with many asserting that the auction model is misunderstood, and many have vented their anger online. Consumer frustration has been reported broadly in both mainstream media, and with popular broadsheet publications. Many have assumed that securing items through this bidding model is analogous with more traditional models. Given the growth within this market segment, it is pertinent to analyse how the penny auction marketplaces function, and to consider whether enhanced disclosure is necessary.

Most pertinently, notwithstanding the nature of such selling models, there appears to be little by way of regulation moderating the activities of such sellers and selling models. This is perplexing given both the similarities and differences between these online selling models and their bricks and mortar equivalents.

While one would anticipate that online auctions, particularly "all-pay auction" models would necessitate greater regulation, it appears evident that trade practices enforcement agencies, and regulatory frameworks have found it challenging to keep pace with the rapid changes in consumer activities, preference and the emergence of several new selling models such as the increasingly popular penny auction online model. Supporting this assertion are West Australian government reviews of the regulation of auctioneers that call into question the adequacy of current regulatory frameworks. Minister McHale, the then Minister for consumer protection; in conducting the review noted the critical importance of auction processes to trade and commerce: "auctions and auctioneers now play a significant role in balancing supply and demand within the economy to ascertain market price. Efficient regulation of the auction industry therefore impacts on the performance of the entire economy."

The review was concerned largely with the Auction Sales Act (1973) (WA) in its application in relation to conventional auctions. This notwithstanding the review did consider the issue of internet auctions at some length. As would be anticipated, the findings of the review asserted: "the concept of an internet auction 
was clearly not contemplated at the time the Act was introduced and no amendments have been made to the Act in response to the advent of Internet auctions." This is arguably true of all Australian auction related legislation within other states, much of which was enacted prior to the advent of the internet. The lack of regulatory response to the observed technological revolution is perplexing; it is perhaps the pace of technological change that is making the framing of a workable regulatory response problematic.

The current paper considers the regulation of online auctioneers and conventional "bricks and mortar" auctioneers from a law and economics perspective. This paper analyses the practices adopted by proprietors of penny auction websites, focusing on the policies adopted by the most popular online sellers. Specifically, the article considers divergence in regulatory standards associated with online auction proprietors and conventional auctioneers operating out of bricks and mortar auctioneering businesses. While the article is written in the context of Australian jurisprudence, the findings are broadly relevant to other jurisdictions. In addition, the article shall posit an alternate model of disclosure, which would ensure greater consumer protection.

It is pertinent to note that there is a dearth of research considering the appropriateness of current models of disclosure and regulation within the penny auction industry. Much of the extant literature considers the underlying structure of the auction model, comparing this alternative model with more familiar models. While some empirical work exists, most of the extant literature employing empirical methods seeks to analyse and quantify the model structure and operation, and shows little regard to regulation and disclosure issues.

\section{Literature Review}

Recent research conducted by Kate Tokeley considered a number of proximate issues regarding relevant jurisprudence from New Zealand [1]. The research was conducted in response to a number of statement made by the New Zealand Minister of Consumer Affairs. Tokeley asserts that the statements made by government indicate that priority has been assigned to ensuring that regulatory pronouncements and technologically neutral. The work of Tokeley is amongst the first to consider the adequacy of current pronouncements in response to technological innovation is the market for online auctions. Tokeley's work is compelling because it highlights the obvious deficiencies of the regulatory apparatus currently operative within New Zealand and offers a series of recommendations that may be somewhat beneficial in responding to the challenges presented by online auctions. Similarly while not concerned with the Australian jurisdiction, the work does offer some insights that are potentially generalizable.

Tokeley notes that the two main risks facing consumers using online auction sites are that the goods are not delivered or that they are defective in some way. The article concludes that there is an urgent need to update the Consumer Guarantees Act $(1993)^{1}$ to expressly cover online auctions. However, this

${ }^{1}$ Consumer Guarantees Act (1993) (Cth of New Zealand). 
amendment alone will not be sufficient to protect consumers using online auctions.

The article articulates well the challenges associated with the regulation of online auctions, though it does not consider the matter of unit bid auctions specifically. ${ }^{2}$ It is contended herein that this auction market warrants specific consideration and is worthy of fuller consideration that has been afforded by the extant literature.

Robert Marshall and Michael Meurer consider the matter of auction regulation, and specifically bidder collusion [2]. Their research asserts that standard analysis of cartel behaviour in posted-price markets is often inadequate when applied to collusion by bidders at an auction or procurement [2]. The authors note that different auction schemes have different levels of susceptibility to collusion, which in turn has implications for resource allocations to ensure enforcement.

The authors assert that auction markets are typically constituted by relatively heterogeneous products, and the bidding party must employ significant resources to understand the nature of the offered item so as to establish the appropriate quantum of funds to bid. This process of price discovery is more complex than the process associated with price discovery in non-auction markets where homogenous goods are made available for sale. Emily Favre considered the approaches adopted by private enterprises in protecting their exposure to online auctions, focusing specifically on luxury brands [3]. Mary Calkins, Alexei Nikitkov and Vernon Richardson consider the regulation of fraudulent activities within online selling environments, though like the Favre study fail to consider unit bid auctions, in favour of eBay selling platforms [4]. Daril Gawith offers a survey of the issues pertaining to the regulation of online transactions in e-commerce [5]. While not specifically an account pertaining to online auctions, the study does consider a number of proximate matters, most notably the significant costs associated with dispute resolution and litigation relating to online commerce. Brandon Peene considers the regulation of online selling platforms and auctions, focusing specifically on the recent Tiffany and LVMH decisions [6].

Peene highlights the need for improved regulation of online auctioneers, and greater clarity in relation to the obligations of online auctioneers in light of Tiffanys. The author concludes that the liability of eBay and similar platforms in relation to brand owners for the sale of counterfeit items remains unresolved on a world-wide basis. This matter along with the regulation of non-similar online auctions such as unit bid auctions remains largely absent from the extant literature, suggesting a genuine dearth of research into online auctions and in particular unit bid online auctions such as penny auctions.

\section{Introduction to Auction Theory and Auction Regulation}

\subsection{Auction Theory, Law and Economics}

Researchers have long devoted attention to auction theory, and it must be as-

${ }^{2}$ Ibid. 
serted that auctions are not a new form of price mechanism. The ancient Greeks employed auction models to assign mining concessions, though most are more familiar with their use of the mechanism for the selling of slaves [7]. In Ancient Babylon, the earliest recorded histories suggest that the Babylonians used auction models to facilitate the sale of wives. The Romans popularised the auction model, adopting auction sales for all manner of goods and commodities [8].

In modern times auction models have been employed largely by both government and the private sector. Consider for example, the assignment of treasury bonds and bills, where bills are assigned based on the prospective acquirer's bid yield. What of government tender processes, where the government puts to tender a service contract or procurement contract, such a process is also an auction, though it is not consistent with our traditional conception of an auction, given these arrangements involve the auctioneer/vendor is seeking the lowest price rather than highest price is sought. Indeed some might even suggest that government lobbying is a type of auction process, albeit an all pay auction where all parties pay but only one party is successful.

Examples from the private sector are too numerous to account for fully within this paper. Consider a few brief examples. Automotive vehicle sales are frequently conducted though auction sale processes. Artwork has been sold through auction processes for hundreds of years. Where two or more rival firms are seeking to acquire the same target the process is akin to a traditional auction.

However, it is the internet and the ease with which an auction mechanism can be created online that has really driven growth in this model for selling. Firms like eBay have become household names as non-traditional auction houses. Indeed the popularity of eBay has resulted in demand for comparable business models. This has resulted in an industry satisfying the demand for such technology. Scripts ${ }^{3}$ to create auction houses online are available cheaply, affording any interested party the opportunity to launch an auction e-commerce website.

Broadly speaking, there are said to be several key auction models from which all other models derive. The most well-known auction models are the first price sealed bid auction and the ascending bid auction. Under the ascending bid model (sometimes referred to as the English auction), arguably the model most consumers are familiar with, the bidders seek to each bid a higher price than rivals until a single bid is left, with all other bidders not prepared to exceed the bid level. Under a first price sealed bid auction model, each bidder is afforded the opportunity to submit a single bid, essentially their "final offer"; this is done privately without other parties being aware of the bid quantum. The bidder submitting the highest offer is successful. This model is consistent with the commonly employed "private sale" model employed in the real estate industry. Other auction models include, reverse auctions, Dutch auctions, Vickery auctions and allpay auctions.

\subsubsection{Reverse Auctions}

A reverse auction is diametrically opposed to a conventional auction, insofar as

${ }^{3}$ Pieces of software, or code that can be incorporated into websites. 
the roles of the parties to the auction are reversed [9]. Under a reverse auction model, a single buyer seeks to secure the goods or services, and allows competing bidders (sellers) to offer their best available price. The bidding parties must ensure that they meet the requirements of the original contract notice, while offering the buyer a favourable price. The selling parties under a reverse auction model seek to win the interest of buyers by reducing their prices in an effort to win over the buyer. For a fuller analysis of this delineation, consider Volk [9].

\subsubsection{Dutch Auctions}

A Dutch auction (sometimes referred to as an "open outcry descending auction") is akin to a sealed first price auction, insofar as each party has the opportunity to offer their best bid price once, all things being equal. The Dutch auction model commences with the auctioneer offering a good or service for sale commencing with the highest auction price, and gradually lowering the price until a price is reached at which a bid is made, with the successful bidder only having to make a single bid, and the auction only being constituted by a single bid [10].

\subsubsection{Vickery Auctions}

A Vickery auction is best understood as a "sealed bid, second price auction", because each bidder submits a price without any knowledge of the bid values lodged by other prospective bidders, and because the price paid is not the highest bidders winning price but the price bid by the second highest bidder.

\subsubsection{All-Pay Auctions}

All-pay auctions are typified by a number of different structures rather than a single unifying structure. They are all however auctioning models, involving all bidding entities paying a sum or sums of money during the auction process. Well known all-pay auction models include the Tullock auction and the Dollar auction.

\subsubsection{Raffles versus Auctions}

A raffle may be understood as conceptually similar to a penny auction however there are some critical differences between each model. A raffle involved the assignment of a ticket or tickets to participants based on the quantum of money expended by the participant, on the initial purchase of tickets. Each ticket confers an opportunity to win a prize or prizes. All tickets are aggregated, with a winner selected. The point at which a ticket is purchased or expended in no way moderates the outcome of the process.

Esther et al. (2007) consider another intriguing and unique and related auction model, the discrete bid English auction, with the authors noting that there is a dearth of research considering non-traditional frameworks. The results offer limited generalizability and assignment to the area of penny auctions given their non-continuous nature. There remains a dearth of research in relation to penny auctions. [11]

Krishna and Morgan offer one of the first analyses of all pay auctions offering 
a coherent framework of analysis. Focusing specifically on revenue the authors contend that expected revenue is greatest under war of attrition conditions. The authors also identify adequate conditions for monotonic symmetric bidding strategies [12].

Augenblick also responds to the dearth of research relating to penny auctions. Augenblick evidences that the bidding behavior may be explained by the naïve sunk cost fallacy. He contends that while bidders make higher profits through time the learning process is identified as slow [13].

\subsubsection{Online Auction Models: Are Online Platform Sellers Auctioneers?}

Broadly speaking, contemporary online auctions fall into the two noted categories: English "style" (traditional) auction models and all-pay action models. ${ }^{4}$ In this study we consider two auction models/auctioneer groups, the eBay model and the "Penny auction" model. The issue of whether an eBay (or bidking.com. au) sale constitutes an auction based sale is a complex one, and is aided by a fuller understanding of each auction framework. Herein, each auction model is considered in greater detail with credence given to the similarities and differences between online and real world auctions. Subsequent emphasis is placed on whether eBay model and penny auction models constitute auctions.

\subsubsection{The eBay Model}

The eBay model, prima facie, appears to resemble real world auctions closely however there are some notable differences. The eBay model is essentially a platform business model with eBay serving as the platform provider. The eBay model is sustained by groups of interested buyers and sellers that promote goods for sale through the eBay website. As such, the eBay model is not a "true" auction model in the conventional sense of the word. While the platform business is generally referred to as an auction model, there are some noteworthy differences between a true auction and the eBay model of online selling.

EBay essentially provides a mechanism for sale of goods and services and an integrated online payment gateway through its online payments facility PayPal. Registered sellers determine the price, description, saleable quantity and duration of eBay "auctions". They upload photographs, descriptors, and other relevant information to induce sale. EBay provides a messaging system between sellers, that allows buyers and sellers to communicate in relation to the listed goods/services but to maintain anonymity nonetheless. Registered buyers, can post questions and make bids on a listed item. The list format can vary, with commonly understood formats like private sale, and ascending bid models

\footnotetext{
${ }^{4}$ Within the noted categories, there are a number of variants. Consider first the English (traditional) model. For clarity's sake, eBay is employed as the central example and theme when analysing these issues in relation to English (traditional) auctions. This example is employed given the general understanding most possess in relation to the eBay model(s), and the need for brevity within these preliminary sections. In relation to "All-pay auction models" this study shall focus on the "penny auction model". Several popular and noteworthy websites serve as examples. Given that the analysis is concerned primarily with penny auctions and given the substantiative research conducted in relation to traditional auction models and the popular eBay model, herewith the ensuing analysis shall focus more on the penny auction model.
} 
available.

The Sellers and Buyers develop a persona within the eBay community, based on item quality, timeliness of the post-sale process (confirmation and delivery) and support; they generate an online approval rating. Other buyers and sellers use such approval ratings to determine whether they want to engage in commerce with fellow community members. EBay serves as a market maker, that in truth shares equal if not greater similarity with the conventional paper based "Trading post newspapers" of bygone eras. EBay does not take possession of goods nor does it moderate quality per se; it merely charges listing fees to the registered sellers.

Pertinently, unlike traditional "real world" auctions, eBay auctions are not moderated by spatial distance, the location of the buyer and seller is of little relevance to the buyers and sellers, beyond the costs and mechanics of transportation. This means that the transactions are not moderated by the geographic location of the parties to the transaction, which it may be argued is at stark contrast with a traditional auction. Traditional auctions are generally understood to occur at a specific geographic location, and while telephony has made off site bidding a possibility since the popularisation of the telephone, it does not enable the same level of off-site participation as eBay style "auctioneering".

This relates to a further critical difference between online auctions and real world auctions, the mechanism for bidding. Most traditional auctions occur through open outcry, with the auctioneer accepting audible bids (or gesture based bids) from individuals attending the auction. EBay auctions are essentially anonymous auctions that result in greater information asymmetries arguably than conventional auctions and buyers are not able to benefit from knowledge of other parties offers. This is pertinent too because eBay enables so called "automated" or "proxy" sales, where the platform initiates a bid on the prospective buyer's behalf based on a buyer proscribed upper limit, when the prospective buyer's bid is exceeded by a rival bid.

Equally relevant is the critical role that auctioneers play in establishing the saleable rights to a given item, is merchantability, its quality, and its authenticity. Real world auctioneers play a critical vetting role that online sellers do not; per se. EBay does not warrant that the goods sold are authentic, or that they are at a merchantable or saleable quality. Equally eBay does not establish the quantity of goods to be sold. In the real world auctioneers have the capacity to provide all of the services noted. EBay lacks the capacity to offer these services and cannot attest to the underlying nature of the transaction, or indeed whether the transaction will be consummated.

Given these differences it is evident that eBay operates merely as a medium for the exchange of goods. It is in essence more of a digital equivalent to the analogue world "classifieds pages" found in print newspapers, rather than a digital equivalent to the analogue world English auction. While the term auction is ascribed to eBay selling in everyday speech, the term eBay auction is part of common parlance, such terminology is errant when used to describe eBay selling. 
This view is supported by Kanchana Kariyawasam and Guy Scott, and they state [14]:

In effect, eBay operates only as an online platform service provider or electronic medium through which bids can be made. EBay does not, in fact, conduct actual auctions and "persons or businesses that assist sellers in placing items for sale on eBay are not conducting an auction or acting as auctioneers". In its actual operation, furthermore, eBay performs functions quite distinct from, and non-equivalent to, those of traditional auctioneers. In reality, eBay neither operates in the same way as traditional auctioneers, nor does it have the same responsibilities as a traditional auctioneer. This raises the significant question, then, as to whether consumers participating in what are superficially or ostensibly "online auctions" are adequately protected when the actual process itself does not, in fact, constitute an auction per se.

As such, eBay quite rightfully should not be captured by extant legislation pertaining to auctioneers, given the key structural differences between each model. While this delineation of the eBay model may be inconsistent with the popular perception of the model and its structure, with many arguably ascribing to the view that the model is an auction model, to consider eBay and analogous models for online selling auctions in the tradition is errant. Whether provisions pertaining to the process of online selling and advertising, and trade practices legislation afford adequate protections to consumers, are entirely separate issues.

\subsubsection{The Penny Auction Model}

The penny auction model in no way resembles the analogue equivalents. The penny auction is not like a traditional ascending bid auction but pertinently penny auctions are in no way similar to eBay selling models. A penny auction in economic parlance is a type of all-pay auction ${ }^{5}$, specifically a bid fee variant of an all pay auction model. All-pay auction models have been used to describe a number of scenarios, from R \& D races, to political lobbing processes. ${ }^{6}$ They are not models that have been ubiquitous like ascending bid auctions within the public sphere. Indeed prior to the advent of the online penny auction it is unlikely that most people would have encountered the model within an analogue market.

While the entomology of the concept and terminology is uncertain, it would appear that the term is consistent with the generalized delineations offered in the unit bid auction literature [15] [16]. However the modern online penny auction

\footnotetext{
${ }^{5} \mathrm{~A}$ war of attrition game is akin to an all-pay auction model. In a war of attrition game each participant continues to participate at their own expense and the expense of other participants. War of attrition games are moderated solely by the resource endowments of each participant. War of attrition games cannot be accommodated using payoff matrices given the potential bids made by participants and as such are more problematic to analyse than many other game theoretic frameworks. Indeed war of attrition games bear striking resemblance to contemporary penny auction models. As such the war of attrition literature is highly relevant to the current study.

${ }^{6}$ Arguably the best known model of an all-pay auction is the Tullock model. Within a Tullock model auction, all bidding parties submit bids, but in this auction structure the successful and unsuccessful parties pay to bid, regardless of whether their bid is successful or not.
} 
is more complex that the model framework posited within much of the extant literature, because it is a multi-participant game with asymmetric information. A penny auction, in economic terms is best understood as a multiplayer game in which all bidders pay for bid units expended in the auction process.

Unlike a traditional auction, the party with the greatest willingness to pay does not necessarily win the auction, because the sequence, and critically the time at which each bid unit is employed determines the likelihood of success; and not merely the willingness to pay.

Let us consider an example. Four geographically dispersed individuals Adam, Bill, Carson, and David are keen to purchase a HDTV. The individuals are unconnected and are keen to purchase a High Definition Television, at the best price. They register with XYZ Penny Auctions Pty Ltd, a well-known online auction website. The Auction house sells bid units for $\$ 1$ per unit. Each bid unit entitles the buyer to a bid on any item within the auction houses portfolio. Each auction is time specific, with the total allotted time starting at 30 minutes. With each additional bid the time rises by a further 20 seconds, to a maximum $30 \mathrm{mi}-$ nutes and 20 seconds. Adam, Bill, Carson and David purchase 110, 100, 90 and 80 bids respectively. The acquired bid units indicate that, all things being equal, Adam has the greatest willingness to pay [17].

As asserted, this does not in any way guarantee success, rather the probability of success is a function of the bid sequence and the number of bidders. Under a conventional English auction model, each party could bid prices they deem appropriate with the party offering up the highest bid the victor. Under such conditions, all things being equal, Adam would secure the television.

As with the eBay model, there are a number of critical distinctions between penny auctions and conventional auctions. Penny auctions like eBay selling are not moderated by geography per se, with participation from a number of geographically dispersed individuals possible.

Unlike traditional auctions, all bidding occurs anonymously through electronic means rather than open outcry. The essentially anonymous nature of penny auctions arguably results in greater information asymmetries than conventional auctions. While buyers are able to benefit from knowledge of other buyers bids, through real time observance, it is impractical to track the level of cost "sunk" (how many bid units have been expended) in the bidding process by any given bidder through the observance of rivals (For further discussion of proximate issues, see [18] [19]). These inconsistencies with conventional auction structures make the penny auction model so worrisome.

However, consistent with conventional auctions occurring in the real world and in direct contrast with eBay selling, penny auction providers do appear to operate as "auctioneers" or in a manner similar in both function and form to auctioneers rather than as platform providers. Rather than providing a platform for buyers and sellers, the penny "auctioneers" offer new goods for sale having determined merchantability/saleability, quality, quantity and authenticity of the goods. It is perhaps this similarity that is the greatest cause for consternation. 
There appears to be little regulation moderating the activities of purveyors of such online auction models. The law appears remarkably inconsistent in its treatment of auctioneers operating through open outcry models and those offering similar services through computer moderated means.

\subsubsection{Penny Auctions an Economic Model}

Let us consider penny auctions in economic terms $P(x)$ equals the probability of an individual bidding $x$, therefore the cumulative of each bidder bidding $\mathrm{x}$ number of bids must be quantified. Consider the probability of a sequence of three bids denoted below.

$$
P(x) \times P(x) \times P(x)=[P(x)]^{3}
$$

As noted the probability that a participant will bid $x$ is $P(x)$, therefore the cumulative probability is $n-1$.

$$
P(x)^{(n-1)}
$$

Let us assume that all bids made by each bidder equate to $x$, so $x$ equals the total number or sum of bids, and $\mathrm{u}$ is the total number of bid units. If we assume that all bidders have the same number of bids and bid sequentially then it does not matter if $\mathrm{u}$ is 1 or 100 or 1000 . If $u$ is 1 the $x=u$.

$$
\begin{gathered}
P(x)=\sum(u)^{(n-1)} \\
P(x)=(x)^{(n-1)}
\end{gathered}
$$

Applying the indifference principle

$$
P(x)=(x)^{\left(\frac{1}{n-1}\right)}
$$

Employing the derivative $p(x)=P^{\prime}(x)$

$$
p(x)=P^{\prime}(x)=\left(\frac{1}{n-1}\right) \sum(x)^{(2-n) /(n-1)}
$$

Solving for the $(x)$ for $p(x)$

$$
(x)=x p(x) d x=\frac{1}{n}
$$

Therefore the value of $x$ gets smaller as the $n$ number of participants increases.

While $\mathrm{n}$ is indeterminate the rational bidder can observe both the frequency of bids and the parties bidding within the auction. They can also observe the number of bids made during prior auctions through the perusal of recently completed auction outcomes.

Therefore the sum of bids per bidder $(x)$ should become smaller as the value of $\mathrm{n}$ becomes larger. So as the number of participants increases the rational bidder should reduce the quantum and or frequency of their bids.

However given the challenges associated with tracking bidding frequencies and the bid unit totals of rival bidders, bidders may not bid rationally. Moreover, bidders are incapable of bidding at their level of marginal benefit as they would within a Dutch auction model as each bid is unitary. Consequently, individuals 
with a lower marginal willingness to pay may succeed the expense of individuals with a marginal willingness to pay. These parameters may give rise to irrational bid frequencies. This notwithstanding, it is important to acknowledge a potentially more deleterious phenomena associated with unit bid auction models. Individuals with large marginal willingness to pay functions may by virtue of the unitary bidding mode expend significant resources in the process of bidding without achieving any bid success. As such, the bids expended represent a sunk cost, however the bidding entity may not perceive them as such. This is known as the naive sunk cost fallacy. It may lead bidders to bid beyond what they may rationally deem to be an appropriate number of total bids. This issue is magnified by many penny auction models that return all bids made by the winning bidder to the winning bidder and only require them to pay the total value of bit units made ${ }^{7}$.

Under traditional Dutch and English auction conditions, bidding parties determine the value of their bid based on their marginal willingness to pay, they have no regard for any sunk costs because no resources are expended with each successive bid. The bidders are not affected by the naive sunk cost fallacy. Under unit bid cost auction conditions each successive bid increases the quantum of sunk cost accruing two bidding parties, this may cause them to allow their quantum of expended bids to impact subsequent bidding behavior. This makes the penny auction bidding structure tantamount to poker machine style gambling where frequently parties have regard to their losses when engaged in subsequent bidding behavior.

\subsection{Regulation of Penny Auctions, Traditional Auctioneers versus Online Auctioneers}

\subsubsection{The Regulation of Auctioneers within the U.S.}

Within the United States of America, there is no federal law pertaining to the regulation of the auction process and auctioneers. The regulation of auctions is therefore left to the states. While not all U.S. states have regulations in place pertaining to auctioneer licensing, most states do regulate auction activity. The basis for much of this legislation is the Uniform Commercial code, adopted by all states except Louisiana. It is pertinent to acknowledge however that the UCC is merely a code of commerce, or guidance document, with little precedent value. It however was the basis for drafted legislation within 49 states.

As a result of the adoption of the UCC, the majority of U.S. state legislatures regulate the activities of auctioneers operating out of "bricks and mortar" auction houses. ${ }^{8}$ The following section briefly outlines some of the standards adopted by

${ }^{7}$ Consider for example, a scenario involving ten bidders within a penny auction model bidding on a DVD. Each bidding party bids one hundred units equating to one dollar and as such the final price for the contested auction good, the DVD, is ten dollars. The successful bidder will receive their 100 bid units back and be required to pay the ten dollar DVD price. As such their net cost is nine dollars, while each other bidder has gained no benefit through the auction but has expended one hundred bid units each.

${ }^{8}$ Given the time of drafting of the UCC, predating the advent of the internet, the UCC did not consider online auction models. 
state legislatures and is not intended to be exhaustive. Significant detail of each pronouncement from with each legislature would result in an inordinately long article. The level of regulation varies across jurisdictions however most of the legislatures adopting stringent standards, regulate the age, nature of training, assessment, license fees, continuing professional development, of auctioneers and conduct of sale and advertising practices adopted by auctioneers [20]. While not all states regulate auction and auctioneer activities, broadly speaking those that have employed a model of regulation require that:

1) An applicant be 18 years or older and possess a high school diploma or the equivalent;

2) Applicants attend a course of study at a state licensing board certified auctioneer program or serve an apprenticeship of six months to two years;

3) Applicants pass an examination of applicable state auctioneer licensing laws;

4) Applicants pay the applicable licensing fees;

5) Applicants complete continuing education courses;

6) Applicants follow state standards for the conduct of a sale; and

7) Applicants adhere to the state standards for advertising auctions.

State legislatures also allow for auctioneers to operate beyond the borders of their state of registration, where relevant licensing reciprocal agreements exist. This allows licensed auctioneers to ply their trade where they have met the standards of accreditation in other states, beyond the state of registration.

The practices adopted by the state legislatures ensure that the licensed auctioneers are well prepared for their duties, and constitute a profession. Critically the licensing framework actively encourages ethical practices and consistent levels of competence, matters of critical importance to any profession. As with most professions, the legislature require on-going education to ensure competence is maintained. Most critically the legislatures require that the auctioneer follows state standards in relation to the conduct of the sales. These practices instill faith within bidders. Consumer can act in good faith knowing that the vendor and auctioneer are required to act in good faith, and conduct themselves in a professional manner. Where consumers believe that the auctioneer has not met his duty of care they can lodge a complaint with the relevant registration body. Where the actions of a registered auctioneer are in violation of the state legislation, there is the potential for the withdrawal of licensing provision and as such the right to operate as an auctioneer. Each state has a grievance process in relation to consumer complaints with many states, providing a mechanism for recompense to the affected party in the event where the actions of the auctioneer, through negligence or design necessitate the provision of such recompense.

While "bricks and mortar" auctioneers (and consequently bricks and mortar auction houses) are closely regulated, the laws for online auction houses are far less developed.

\subsubsection{The Regulatory Framework within Australia}

Within Australia, the approach adopted by the states in relation to auctioneer 
registration was somewhat consistent, however unlike the U.S. there appears to be no legislation requiring the operators of online auction houses to meet the same exacting standards as traditional "bricks \& mortar" businesses. Moreover, the Australian industry is now largely less regulated that the U.S. industry, though consumer harm is moderated through consumer protections legislation.

Licensing regimes have differed somewhat within Australia historically, with some states requiring that auctioneers be licensed, while others not enacting any specific legislation necessitating the licensing of auctioneers. While at present, only Queensland and Western Australia require that auctioneers be licensed, a number of jurisdictions previously required that auctioneers be regulated. Victoria, Western Australia, the Northern Territory and the Australian Capital Territory have all previously enacted legislation requiring the licensing of auctioneers, with licensing requirements in these jurisdictions displaying strong similarity. The licensing regimes evident in Queensland and Tasmania were considered the most onerous, and differed somewhat from other jurisdictions, adopting a more onerous set of requirements for licensing. South Australia and New South Wales, differed from other jurisdictions historically, insofar as they did not require any specific licensing beyond licensing that may be required to operate in compliance with other acts, such and the Pawnbrokers Act, and the Stock Agents Act.

The obvious differences evident within licensing regimes caused the recognition of auctioneering professionals across jurisdictions to be problematic. This was been noted by a number of competition reviews that sought to promote greater mutual recognition of licensing arrangements. Indeed governments have recursively sought to come together to enable better mutual recognition of qualifications and licensing across jurisdictions, and auctioneers have been considered during such discussions. The governments initiated the Vocational Education, Employment and Training Committee (VEETAC). The committee concluded that the licensing requirements for a number of professions be removed, with auctioneers amongst the professions where such a recommendation was made.

During the 1990s, a number of jurisdictions removed their requirements for licensing, with licensing now only required within Queensland and Western Australia. These decisions were made notwithstanding the potentially deleterious impacts of such deregulation on consumer interests. Interestingly there are no specific provisions in place to moderate the actions of online auctioneers, with recent reviews of auction regulation noting that at the time of drafting online auctions were not anticipated. Australian jurisdictions have seen little value in licensing auctioneers operating out of traditional bricks and mortar operations, and logically this has translated to a similarly lassie faire approach being adopted to online auction houses.

Interestingly it would appear that there is little credence afforded to the burgeoning "penny auction" model notwithstanding the significant consumer criticism cited by the state consumer protection agencies. There is no legislation 
in place within any Australian jurisdiction concerning the activities of online auctioneers. Recently, Consumer Affairs, Victoria appeared to grow so concerned about the issues created by this new business model that it issued the following alert notice:

"Penny" or "bidding fee" auctions are a relatively new form of online buying. Participants enter an online auction to purchase heavily discounted goods and services, paying a non-refundable fee for every bid.

The price rises with each bid as participants try to purchase the discounted item. The last participant to bid when the time limit expires gets the item. However, the final bid is not the total cost; the total cost is the final bid price plus the cost of bidding.

Consumers should also be wary of disreputable sites, which may use computer generated bidding (called "bots") to drive the cost higher. Another practice called "shilling" involves site operators using a third party to place dummy bids to drive the cost higher.

If you plan to take part in a penny auction, research the site you intend to use, ensure you read all of the terms and conditions carefully and keep the true cost in mind. ${ }^{9}$

The statement suggests a degree of confusion on the part of consumers, and perhaps a disregard or misunderstanding amongst consumers about the bid unit costs when determining the price of goods. While the auction industry is now less regulated, with few licensing regimes in operation other than those within Queensland and Western Australia, and those necessitated by other meeting compliance requirements of other related acts, such as the Stock Agents Act, legislative protections exist through the consumer protection legislation. The adequacy of current pronouncements will be considered currently.

\subsubsection{The Adequacy of the Regulation of Online Auctioneers}

It is apparent that the legislative pronouncements that govern the activities of auctioneers have not kept pace with technological change. The pseudo online auction models that predominate on the internet are better understood as platform based models, or sale facilitation models and as such are not true auctions. The eBay model has already been acknowledged as such herein. It is essentially an example of a platform seller business, akin to a classified section within a newspaper. Yet, there are a number of traditional auctions now moderated using the internet, and auction houses using their online presence to offer more conventional auctioneer services. These auctioneers are not merely providing a platform for vendors to make good available to potential purchasers but rather are operating as auctioneers online. The increasingly popular penny auction models are also commonly observed online, and yet remain largely unregulated. Given the significant complaints parlayed at such models and the significant potential for consumer harm, this lassie faire approach appears unwise, or at the least worthy of further consideration.

${ }^{9}$ http://www.consumer.vic.gov.au/shopping/online-shopping/penny-auctions 
The nature of the internet makes it possible for individuals and organizations around the world to provide traditional auction services online while not meeting the requirements of Australian jurisdictions, in relation to licensing and compliance. This is arguably the most critical challenge to reform, the ease of avoidance, particularly in relation to regulation of online auctions. The critical challenge for regulators is to how jurisdictional issues can be moderated.

The question arises as to whether there is need for greater regulatory oversight of penny auctions given their unique nature, and the significant potential for loss and consumer harm, and whether computer mediated selling methods enable greater regulatory avoidance. These questions give rise to two relevant considerations. Firstly, whether broader consumer protections contained in the Competition and Consumer Act (2011), provide adequate protections to consumers given the somewhat unique and confusing nature of penny auction models. Secondly, whether computer mediated auction selling models enable greater regulatory avoidance; and given the potential for regulatory avoidance whether such selling methods necessitate greater regulatory oversight.

The obvious challenges associated with regulating online vendors operating online auction houses and more contemporary penny auction models is that any regulatory pronouncement would place the local industry at a distinct disadvantage to foreign rival firms. Local entities that meet the expectations of any local licensing regime would face firm competition from non-compliant entities operating from abroad, where in many cases there is a dearth of legislation moderating their activities.

By virtue of the anonymity afforded by the internet to participants engaging many internet based activities it is arguable that they could be employed more easily to engage in unlawful activities. The claims made in relation to internet auctions and auction-like processes are too numerous to recount fully but include non-delivery of goods by vendors, misleading advertising and the quality of goods being misrepresented.

\subsection{The Adequacy of Consumer Protections Enacted Through the Competition and Consumer Act}

Australian Trade practices legislation sought to afford significant protections to consumers; these protections have been extended within the Australian Consumer Law. The ACL extends upon the implied warranties of the TPA, by enacting a number of consumer guarantees that cannot be removed through contract. Consumers making purchases online are entitled to the same protections as individuals making purchases through offline purchasing arrangements, for example those transacting through mail order, over the counter, or purchasing through door to door selling arrangements. These protections are afforded to the extent that the purchaser meets the definition of consumer.

It is noteworthy that the TPA was silent in relation to the application of provisions within the digital economy beyond "telegraphic \& telephonic" activities. Given the time at which the pronouncements were drafted, it is logical that 
the drafters of the legislation could not have envisaged the creation and growth of the digital economy and the advent and emergence of the internet, and internet mediated communications tools.

Rhonda Smith asserted that:

The Trade Practices Act 1974 (Cth) is, however, generally silent as to whether its provisions apply to conduct carried out electronically, although the breadth of its controls would arguably apply to all online activities carried out between corporations and consumers. Most of the consumer protection provisions of the Act specifically apply to conduct which "involved the use of postal, telegraphic or telephonic services" (s. 6(3) which would seem to exclude the internet and email which are not specifically telephonic) $[21]$.

While the terms online and internet are not a feature of the provisions, it is likely that they would nonetheless be captured by the provisions, as neither is specifically excluded [14].

In relation to the sale of goods or services, the TPA extended a significant number of protections to consumers. Section 53, affords consumers protections in relation to misleading representations made about a good or service. Section 58 makes unlawful the acceptance of monies absent of an intention to supply, or to supply goods that are materially different to those offered and accepted through a sale of goods transaction. Section 70 is largely concerned with ensuring that goods provided are consistent with the delineation offered in relation to the goods. Section 71(1) makes unlawful the supply of jobs by a corporation where such supply is not of a merchantable quality. Section 71(2) asserted that goods must it suited to the purposes noted by the consumer to the vendor at the time of sale or through the process by which the sale has been facilitated.

Kariyawasam noted that:

The implied conditions ss. 70(1), 71(1) and 71(2) do not apply to the sale of goods by auction. The author claims that Australian businesses could potentially use eBay to dispose of goods which are not of merchantable quality, or are not fit for purpose, without being hindered by these implied terms. State based Sale of Goods Acts may imply similar terms into these transactions, but those terms can generally be excluded through contract, whereas the TPA implied terms cannot be excluded, in accordance with s.68. These provisions are especially pertinent to online transactions, as the consumer is not able to physically inspect the goods before buying them.

Additionally, the TPA did afford extraterritorial effects, seeking to protect Australian consumers from vendors beyond Australian shores [14]. Specifically, ss. 5(1), 6(1) and 6(3) sought to afford protection to Australian consumers from prohibited conduct of vendors abroad, offering a limited number of remedies.

Since 2010, a number of worthwhile reforms have been progressively implemented, greatly improving Australian Consumer Law. Pertinently, the reforms 
seek to afford the community a more proactive and nationally consistent. Many of the former TPA prohibitions have been moved within the new pronouncements but at their core remain largely the same as the former pronouncements. This is certainly true of the provisions pertaining to unconscionable conduct, misleading conduct and false/misleading representations.

Amongst the most substantiative changes enacted are the new consumer guarantees, these guarantees replacing the implied warranties evident under the TPA. The new guarantees appear to be heavily influenced by the New Zealand Consumer Guarantees Act 1993. The consumer guarantees cannot be excluded. The ACL offers a series of remedies for failures to comply with a consumer guarantee. These guarantees do not apply where the sale occurs between an individual and other individuals or businesses. They are also not applicable to traditional auction environments where an auctioneer operates as an agent on behalf of a seller. The guarantees would apply to sales where a business employs an online website or auction site to sell goods or services, where the auction website does not have an agency relationship or seek to represent the seller. Therefore, the guarantees would apply to business sellers on eBay as well as the promoters of penny auction websites such as bidking.com.au.

The new prohibitions for false and or misleading conduct are arguably the most beneficial to consumers purchasing goods online and in particular those purchasing through online auction mechanisms such as conventional English auctions online and online penny auctions. The new ACL provisions sought to expand upon the related provisions within the TPA. Section 18 of the ACL, replacing s.52 of the TPA, specifically prohibits a person from engaging in misleading and/or deceptive conduct. The jurisprudence relevant to 5.52 remains applicable to s.18. The prohibition is not limited to the supply of goods or services.

While recent changes to ACL appear meritorious, they do little to address the issues raised by this article. Most critically, none of the provisions within the ACL address directly disclosures relating to the sale of goods using non-conventional auction models, such as Tullock or unit bid auction models.

Clear disclosure of a non-conventional (Non English/Dutch model) bid model may be necessary, and amendments to consumer provisions relating to the sale of good may be highly beneficial. Such disclosure would ensure that many of the issues highlighted by consumers would be ameliorated. A clear delineation of the bidding structure would ensure that buyers and sellers could operate in good faith, and confidence in the penny auction market.

\subsection{Possible Reform to Regulations of Online Penny Auctions and All-Pay Auctions}

\section{National Licensing Scheme for Unit Bid Auctions}

A national licensing scheme for unit bid auctions would represent a parsimonious and low cost mechanism through which all-pay auction structures could be regulated. A licensing scheme could, for example, ensure that licensed entities 
meet basic disclosure and user education requirements thus improving the overall structure of the market.

While it would appear evident that relatively popular platform based selling businesses adopting eBay style selling models are not operating as true online auction houses, consumer protections exist to protect those engaging with such models, particularly where businesses employ such models to engage in the sale of goods. Such models are also consistent with what are arguably the most familiar styles of auction based selling (traditional English auctions), and as such are less likely to create confusion by virtue of their bid mechanism.

This is not true of unit bid/all-pay auctions and as such it would appear that in relation to such auctions, the existing consumer protections do little to protect those participating from limited bidding mechanism related disclosure information. A national scheme would ensure that consumers would be able to participate within penny auction markets with greater confidence.

As noted, the obvious challenge with any regulatory regime remains. Any licensing regime would assign greater compliance costs to local entities and would place them at a disadvantage to foreign firms. Such an approach may also encourage "jurisdiction shopping", where prospective operators of penny auctions and related all pay auction models establish themselves within polities evidencing very limited regulations in relation to auctions and online selling models.

However, empirical evidence suggests that the auction markets and in particular online auction markets are heavily reliant on trust. A trust engendering device such as a licensing regime may have the potential to moderate the spending behaviours of participants. Where a purchaser observes both a licensed and an unlicensed penny auction vendor online, the participation of an entity within a licensing regime is likely to influence the behaviour of the prospective purchaser significantly.

\section{Concluding Remarks}

Auctioneering was once largely an offline activity, synonymous with dusty rooms and numbered handheld placards. This selling approach has changed dramatically with the advancement of technology, and online auctions are now the popular mode of auction sale. The significant deregulation of the auction industry has meant that auctioneers operating in both online and offline auctioneering environments, are now operating within an industry largely absent of a licensing regime, notwithstanding the regulatory apparatuses in effect within Queensland and Western Australia.

Other jurisdictions do not require any specific licensing beyond licensing that may be required to operate in compliance with other acts, such as the Pawnbrokers \& Second Hand Dealers Act and the Stock Agents Act. While this ensures that there are a number of additional protections in place in relation to a number of offline auction markets, such as the property market, the deregulation and pertinently the removal of licensing regime, which has meant that consumers benefit from only a limited set of protections when acquiring goods through 
auction mechanisms.

New categories of auction that have not been evident historically in offline markets are now becoming popularized online. This is certainly true of penny auctions and related unit bid auctions. The absence of licensing regimes has meant that many providers of such auction mechanisms have gone largely unlicensed and unregulated.

\section{References}

[1] Tokeley, K. (2016) Towards a New Regulatory Regime for New Zealand Online Auctions. New Zealand Law Review, 2011, 91-119.

[2] Marshall, R.C. and Meurer, M.J. (2004) Bidder Collusion and Antitrust Law: Refining the Analysis of Price Fixing to Account for the Special Features of Auction Markets. Antitrust Law Journal, 72, 83-118.

[3] Favre, E. (2007) Online Auction Houses: How Trademark Owners Protect Brand Integrity Against Counterfeiting. Journal of Law and Policy, 15, 165.

[4] Calkins, M.M., Alexei, N. and Richardson, V. (2008) Mineshafts on Treasure Island: A Relief Map of the EBay Fraud Landscape. Pittsburgh Journal of Technology Law \& Policy, 8, 1. https://doi.org/10.5195/tlp.2008.42

[5] Gawith, D. (2006) Non Litigation-Based Redress for International Consumer Transactions Is Not Cost Effective-A Case for Reform? Murdoch University Electronic Journal of Law, 3, 115-150.

[6] Peene, B. (2010) Lux for Less: EBay's Liability to Luxury Brands for the Sale of Counterfeit Goods. Seton Hall Law Review, 40, 1077-1115.

[7] Shubik, M. (2004) The Theory of Money and Financial Institutions. MIT Press, Cambridge.

[8] Doyle, R. and Steve, B. (2002) History of Auctions: From Ancient Rome to Today's High-Tech Auctions. The Auctioneer, Vol., page.

[9] Volk, D.B. (2007) Principles-Oriented Approach to Regulating Reverse Auctions. Public Contract Law Journal, 37, 127-139.

[10] Oh, P. (2007) The Dutch Auction Myth. Wake Forest Law Review, 42, 853.

[11] Siegel, R. (2009) All-Pay Contests. Econometrica, 77, 71-92. https://doi.org/10.3982/ECTA7537

[12] Krishna, V. and Morgan, J. (1997) An Analysis of the War of Attrition and the AllPay Auction. Journal of Economic Theory, 72, 343-362. https://doi.org/10.1006/jeth.1996.2208

[13] Augenblick, N. (2009) Consumer and Producer Behavior in the Market for Penny Auctions: A Theoretical and Empirical Analysis. Stanford University, Stanford. http://www.stanford.edu/ ned789

[14] Kariyawasam, K. and Scott, G. (2008) Contractual Legalities of Buying and Selling on EBay: Online Auctions and the Protection of Consumers. Journal of Law, Information and Science, 19, 42.

[15] Engelbrecht-Wiggans, R. and Kahn, C.M. (1998) Multi-Unit Auctions with Uniform Prices. Economic Theory, 12, 227-258. https://doi.org/10.1007/s001990050220

[16] Vickrey, W. (1962) Auctions and Bidding Games. Recent Advances in Game Theory, $29,15$.

[17] David, E., Rogers, A., Jennings, N.R., Schiff, J., Kraus, S. and Rothkopf, M.H. (2007) Optimal Design of English Auctions with Discrete Bid Levels. ACM Transactions 
on Internet Technology, 7, 98-107. https://doi.org/10.1145/1239971.1239976

[18] French, K.R. and McCormick, R.E. (1984) Sealed Bids, Sunk Costs, and the Process of Competition. Journal of Business, 57, 417-441. https://doi.org/10.1086/296273

[19] Easterbrook, F.H. and Fischel, D.R. (1982) Auctions and Sunk Costs in Tender Offers. Stanford Law Review, 35, 1-21. https://doi.org/10.2307/1228378

[20] Milgrom, P.R. (2004) Putting Auction Theory to Work. Cambridge University Press, Cambridge. https://doi.org/10.1017/CBO9780511813825

[21] Smith, R.L. (2000) When Competition Is Not Enough: Consumer Protection. Australian Economic Papers, 39, 408-425. https://doi.org/10.1111/1467-8454.00101

Submit or recommend next manuscript to SCIRP and we will provide best service for you:

Accepting pre-submission inquiries through Email, Facebook, LinkedIn, Twitter, etc. A wide selection of journals (inclusive of 9 subjects, more than 200 journals) Providing 24-hour high-quality service User-friendly online submission system Fair and swift peer-review system Efficient typesetting and proofreading procedure Display of the result of downloads and visits, as well as the number of cited articles Maximum dissemination of your research work

Submit your manuscript at: http://papersubmission.scirp.org/

Or contact tel@scirp.org 